\title{
Cólera, paixão e morte: a representação de Afrodite no Hipólito, de Eurípides
}

\author{
GIULIANA RAGUSA \\ Departamento de Letras Clássicas e Vernáculas \\ Faculdade de Filosofia, Letras e Ciências Humanas \\ da Universidade de São Paulo
}

\begin{abstract}
RESUMO: Este artigo consiste no estudo da personagem de Afrodite no Hipólito, de Euripides, que a representa sob os signos da cólera, da paixão e da morte. Para tanto, a análise do monólogo da deusa, com o qual ela abre a tragédia e ao término do qual ela deixa definitivamente a cena, será a chave, mas serão, ainda, consideradas outras cenas da peça nas quais Afrodite é referida, passagens de poemas épicos, relatos de fontes antigas e reflexões sobre a religião e os cultos gregos. Desse modo, pretendo enfatizar a singularidade da Afrodite concebida por Eurípides no Hipólito, bem como nela identificar ecos de outras "Afrodites" gregas literárias e cultuais.
\end{abstract}

PALAVRAS-CHAVE: Afrodite; Hipólito; Euripides; cólera; paixão e morte.

\section{Comentário inicial}

"No período clássico, Afrodite, que era objeto de diversos cultos em Atenas, tornou-se o símbolo supremo de érōs" (Stanford, 1983, p. 36). Como personagem, Afrodite é a implacável, poderosa e irresistível deusa do amor - não o romântico, associação imediata para nós, herdeiros do Romantismo do século XIX e de valores judaico-cristãos, mas o sexual, o erótico. De todas as tragédias gregas, o Hipólito, de Eurípides (485-406 a.C.), parece trazer à cena a representação mais marcante e terrivel de Afrodite que, mesmo após abandonar o palco ao fim de seu monólogo de abertura, faz-se presente no decorrer do enredo, pairando sobre os acontecimentos como prenúncio da desgraça por ela engendrada e anunciada.

Ao debruçar-se sobre a Afrodite do Hipólito, este texto visa ao estudo da personagem divina construída sob os signos da cólera, da paixão e da morte. Para tanto, a análise do monólogo da deusa é essencial, mas a ela serão associadas, ainda, referências a outras cenas da tragédia, bem como incursões por passagens de poemas épicos nos quais há uma pluralidade de representações de Afrodite, criadas, segundo as exigências específicas de cada poe- 
ta e de cada gênero literário, a partir do universo mítico-religioso que a cerca, o qual será também considerado.

Passo, pois, ao monólogo de Afrodite, ressaltando que as traduções do grego para 0 português e de citações de obras em língua estrangeira são minhas, salvo as exceções devidamente indicadas.

\section{Estudo de Afrodite no monólogo do Hipólito}

O monólogo de Afrodite (vv. 1-57), na primeira parte do prólogo (vv. 1-120) do Hipólito $^{1}$ (Hip.), surpreende e deixa atônito o leitor - e, decerto, o espectador -. porque traz ao palco uma deusa violenta e impiedosa a proferir um discurso de vingança e desgraça. Ao fim do monólogo, essa personagem abandona, definitivamente, a cena. Por isso e pela riqueza de elementos nele contidos, o monólogo merece uma leitura detida. Dividindo-o em blocos, tal leitura pretende ressaltar as características e as dimensões de Afrodite na tragédia e, assim, estudar o seu próprio enredo, bem como o mito que lhe é subjacente. No primeiro bloco (Hip. 1-8), a deusa se apresenta:

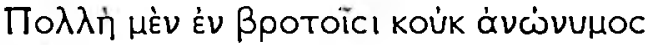

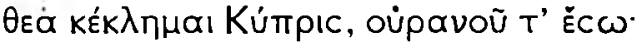 \\ "Poderosa entre os mortais e célebre no céu, chamo-me a deusa Cípria".}

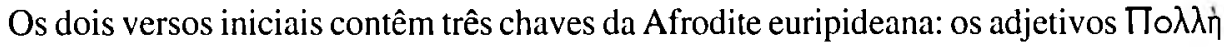

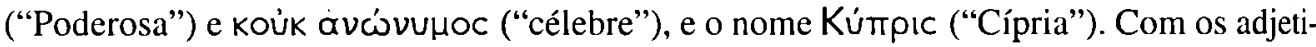
vos, a deusa reafirma seu poder entre os homens e sua glória no Olimpo, e, assim, dá o tom de sua fala - o tom da violência que marcará todo o desenrolar da ação da tragédia. Quanto a Kúmpıc ("Cípria"), esse é, "incontestavelmente, o nome da deusa mais largamente atestado na literatura" grega (Pirenne-Delforge, 1994, p. 317) e, para alguns, é "indubitavelmente, um título local grego" em Chipre (Farnell, 1896, p. 619).

Afrodite é chamada Kúmpıc pela primeira vez, para nós, no canto 5 da llíada, no qual se repete por cinco vezes ${ }^{2}$. Embora na Odisséia Kúmpıc não ocorra ${ }^{3}$, a conexão entre a deusa e a ilha de Chipre é estabelecida de modo diverso, qual seja, pela referência à cidade cípria de Pafos no canto 8 do poema, ao final da canção sobre o amor de Ares e Afrodite que Demódoco entoa na ilha dos feáceos (vv. 266-369).

Diz tal canção que, após ser flagrada em adultério pelo marido traído, Hefesto, que a acorrentara ao leito junto a Ares, o amante, e tendo sido exposta aos olhares dos outros deuses, Afrodite refugia-se em Chipre (Od. 8, 362-6)

\footnotetext{
A edição adotada para este estudo é a de W. S. Barrett, 1992.

2 Cf. vv. 330, 422, 458, 760, 883; Boedeker, 1974, p. 19.

3 Cf. Boedeker, 1974, p. 19-20.

4 Texto grego: edição Loeb, Homer, The Odyssey - I, 1976.
} 


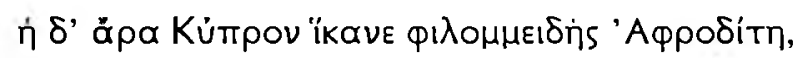
És П’́q

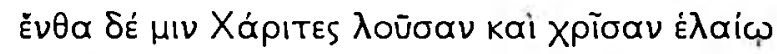

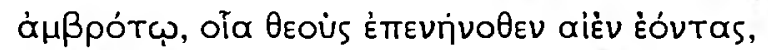

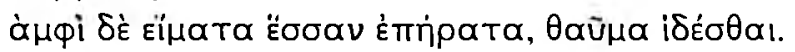
"E em Chipre chegou a amante-dos-sorrisos, Afrodite, em Pafos; lá, o seu recinto sagrado e o seu altar fragrante.

E lá as Cárites a banharam e a ungiram com óleo imortal, do tipo que cobre os deuses que sempre são, e a envolveram em vestes adoráveis - maravilha de se ver".

O culto de Afrodite em Pafos era antigo e famoso, atestam fontes antigas, dentre as quais o viajante Pausânias (século II d.C.), que relaciona, no seu livro sobre a Arcádia, a fundação da cidade e do santuário da deusa à viagem de retorno do arcádio Agapenor, um dos muitos heróis helenos que para casa voltaram após a queda de Tróia ${ }^{5}$. Noutro livro, sobre a Ática, ele faz nova menção ao santuário da deidade em Pafos, indicando suas origens orientais, quando aponta, em Atenas, perto do templo de Hefesto, o "santuário (...) de

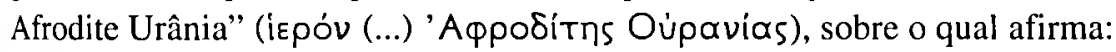

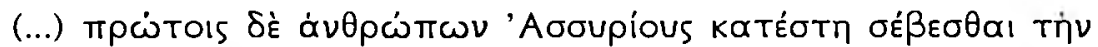

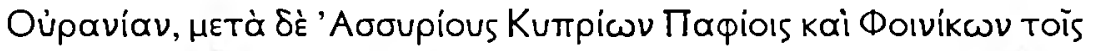

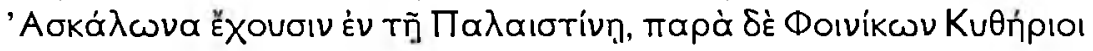

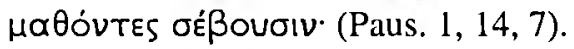

"Os assírios foram os primeiros homens a estabelecer o culto à Urânia, e, depois dos assírios, os páfios de Chipre, e dentre os fenícios, os habitantes de Ascalão, na Palestina, com os quais o povo de Citera aprendeu a cultuá-la"6.

Havia um templo de Afrodite em Atenas, mas o culto à deusa veio do Oriente, dos assírios, via Chipre e Citera7; o próprio epíteto da deusa, Oủpavías ("Urânia"), estaria,

' Cf. Burkert, 1998, p. 153; Pausânias 8, 5, 2 (ed. Loeb).

6 Todas as citações do texto grego de Pausânias são feitas a partir das edições Loeb (vide bibliografia)

1 Cf. Morgan, Aphrodite Cytherea, 1978, p. 117. Vide Heródoto, sobre o templo de Afrodite

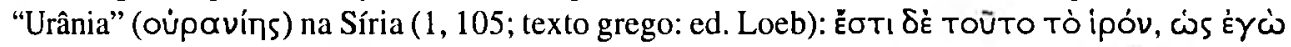

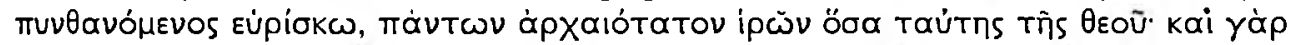

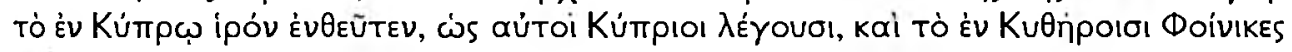

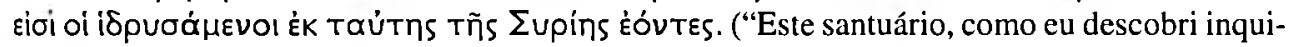
rindo, é o mais antigo de todos os da deusa, pois o santuário em Chipre foi fundado a partir dele, como dizem os próprios cíprios, e o de Citera os fenícios, habitantes dessa terra da Síria, são os

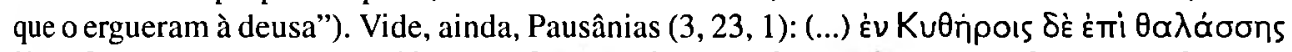

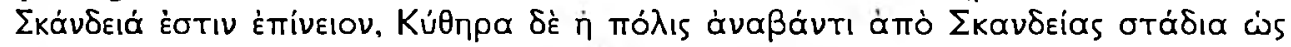

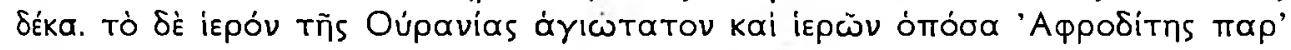

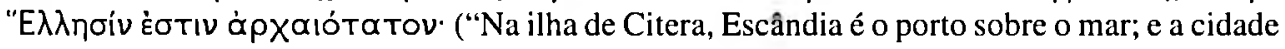


segundo L. R. Farnell em The Cults of the Greek States - II, ligado ao seu culto oriental (Farnell, 1896, p. 630). Fica, pois, atestada tanto na poesia e quanto no relato histórico a antigüidade dos cultos a Afrodite nas duas ilhas; daí a relevância incontestável sobretudo de Chipre nas representações literárias da deusa. Ressalto que, no Hipólito, o nome Kúmpic ("Cípria"), predomina sobre 'Aфробítn (“Afrodite").

Dada a sua posição geográfica, Chipre agrega e mescla as culturas orientais e a cultura grega (Pirenne-Delforge, 1994, p. 319-23). O mesmo se dá com Afrodite, deusa do panteão heleno que guarda, em sua imagem, elementos típicos do Oriente, tais como o luxo dos tecidos que a vestem, os seus adereços, os perfumes, o ouro. Além disso, a divindade, segundo os antigos, como Pausânias e Heródoto, teria sido trazida à Grécia por povos orientais. Por fim, há que se destacar que os cultos de Afrodite dominavam nas ilhas de Chipre, Citera, Creta, e nas cidades gregas da costa da Ásia Menor (Farnell, 1896, p. 618)9.

Essa ambigüidade de Afrodite, deusa grega marcadamente oriental, reflete-se, pois, nas suas origens, na geografia de seus cultos, nos mitos que a cercam, na composição de sua figura literária e, também, no seu principal atributo, o amor erótico-sexual, considerado, pelos gregos, como uma força selvagem, estrangeira, da qual não se pode fugir, a qual não se pode rejeitar impunemente. A própria deusa diz isso no seu monólogo do Hipólito, após ter se apresentado (Hip. 3-8):

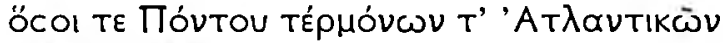

$$
\begin{aligned}
& \text { VaioucIV Elı }
\end{aligned}
$$

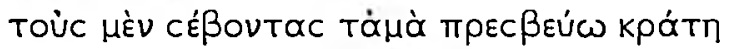

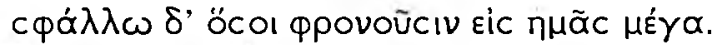

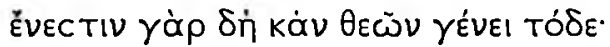

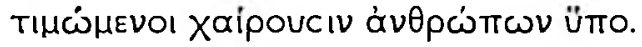

$$
\begin{aligned}
& \text { "De quantos entre o Ponto e os limites de Atlas } \\
& \text { habitam, olhando a luz do sol, } \\
& \text { eu honro os que reverenciam meu poder, } \\
& \text { mas abato os que me desafiam, } \\
& \text { pois até isto pertence à estirpe dos deuses: } \\
& \text { alegrarem-se em serem honrados pelos homens". }
\end{aligned}
$$

Em certas passagens da llíada e do Hino Homérico a Afrodite, a divindade mostra sua face perigosa. No terceiro canto da Ilíada, Helena é advertida quando, exaltada e esquecida da reverência devida à deusa (Friedrich, 1978, p. 60), ensaia uma revolta contra Afrodite, recusando-se a deitar com Páris. Então, a deusa a ameaça (Il. 3, 414-7):

de Citera, para quem sobe, está a dez estádios de lá. O santuário da Urânia é o mais sagrado e, dentre todos os santuários de Afrodite na Grécia, o mais antigo".).

8 Cf. para Kúmpic os versos 2, 31, 101, 110, 117, 359, 372, 401, 415, 443, 448, 465, 522, 553,

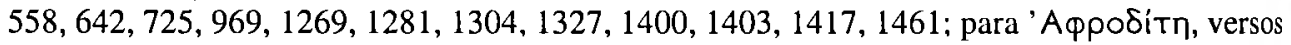
$532,539,765$.

9 Para discussão das origens de Afrodite, Farnell, 1896, p. 618-29 e Pirenne-Delforge, 1994, p. 1-13. 


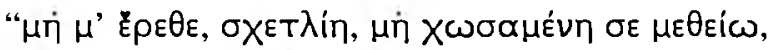

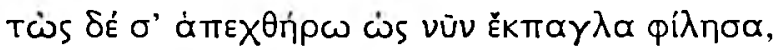

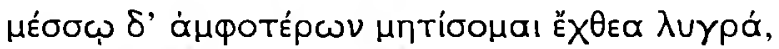

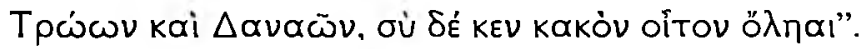

"Mísera, não me incites. Se me encolerizas e te deixo, terás meu ódio em vez do amor.

Se entre os Aqueus e Troianos eu suscitasse ira lutuosa contra ti, de má sorte morrias". ${ }^{10}$

Ao término do Hino Homérico a Afrodite, que transcorre leve até que Afrodite, após ter se deitado com Anquises, a ela revela sua identidade (vv. 1-176), ouvimos os acordes da cólera vingativa: a deusa lança sobre a atmosfera da paixão o manto da morte, uma de suas facetas". Reproduzo as palavras ameaçadoras de Afrodite a exigir de Anquises o sigilo sobre sua união amorosa com ela, a mentira sobre a verdadeira filiação de Enéias, fruto daquela união, e o respeito à ira divina (H. Hom. Afr. 287-290 $)^{12}$ :

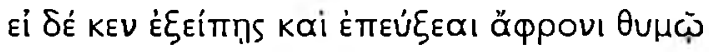

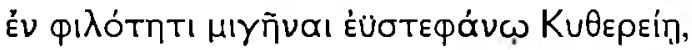

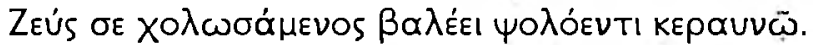

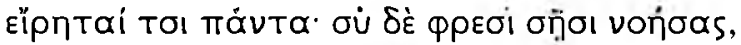

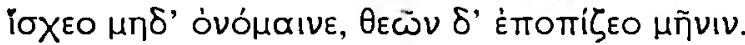

"Se contares e te vangloriares em teu tolo coração que te uniste em amor à Citeréia de bela guirlanda, Zeus, em cólera, lançará contra ti um raio em brasa.

Disse-te tudo já. Tu, refletindo em teu peito, contém-te e não digas meu nome, mas reverencia a ira dos deuses".

As figurações anteriormente relembradas desenham uma Afrodite similar àquela do Hipólito, muito embora a tragédia realce seus traços mais sombrios desde o primeiro verso. No segundo bloco do monólogo da peça, que vai dos versos 9 ao 23 , a deusa resume o motivo de sua ira, o que explica suas palavras iniciais (Hip. 9-23):

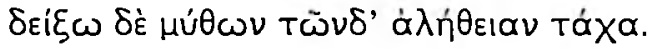

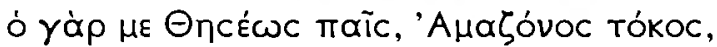

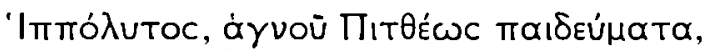

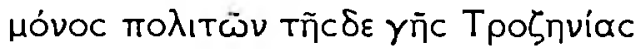

${ }^{10}$ Texto grego e tradução da edição de Haroldo de Campos, lliada de Homero: volume I, 2001.

"Cf. Farnell, 1896, p. 652; Pirenne-Delforge, 1994, p. 440: “(...) les prérrogatives chtoniennes d'Aphrodite ne constituent pas l'envers de son rôle habituel, mais émanent d'un imaginaire qui l'associait dès l'origine aux puissances "noires", c'est-à-dire nocturnes et inferneles".

12 Texto grego do Hino Homérico a Afrodite: edição Allen, Halliday \& Sikes, The Homeric Hymns, 1980. 


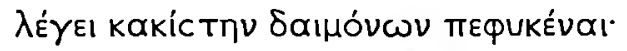

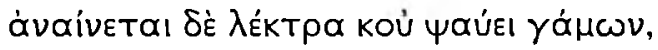

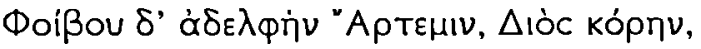

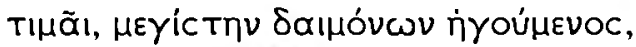

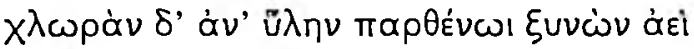

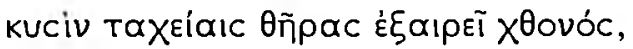

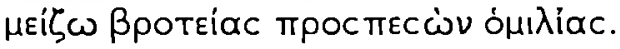

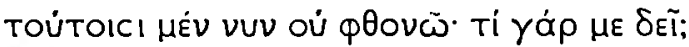

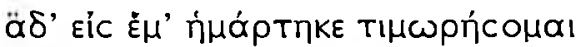

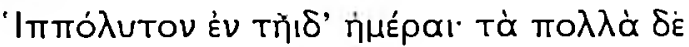

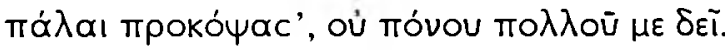

"Logo provarei a verdade de meu relato.

De Teseu o filho, da Amazona rebento -

Hipólito, o pupilo do sagrado Piteu -,

só ele, dentre os cidadãos desta terra de Trezena,

diz que sou a mais vil dentre as divindades,

rejeita o leito do amor e renuncia ao casamento,

mas a irmã de Febo, Ártemis, a menina de Zeus,

honra-a, a maior das deidades considerando-a.

Sempre acompanha a virgem pela floresta verde,

e alivia a terra das feras, com seus cães velozes,

caído num companheirismo maior do que o humano.

Todavia, não invejo isso. Por que deveria?

Mas do que contra mim ele errou, eu me vingarei

de Hipólito neste dia. Para isso, muito já está

feito há tempos; não preciso de muito mais trabalho".

Afrodite relata: Hipólito é o filho bastardo de Teseu com uma Amazona, que cresceu em Trezena sob a tutela de Piteu, seu bisavô, avô materno de Teseu e antigo rei da cidade (Barrett, 1992, p. 157). A seguir, a deusa elenca os erros do jovem: difamação, rejeição ao sexo e ao casamento e, além disso, somente a Ártemis ele reverencia, acompa-

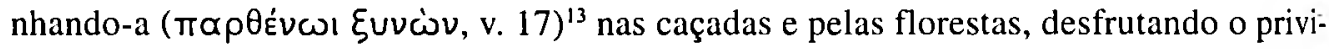
légio de sua companhia. O verso 20 evidencia que incomoda Afrodite não a adoração de Hipólito a Ártemis em si, mas o fato de tal adoração implicar a sua exclusão. A deusa declarou: ela poupa os que a honram, mas abate os que não o fazem, pois aos mortais cabe

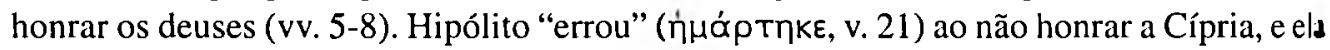
o punirá (vv. 21-2).

13 Cf. Barrett, 1992, p. 157: "cuveĩvaı Yuvaıkí is ordinarily used in a sexual sense; the sense is not ignored here, but $\pi \alpha \rho \theta \dot{\varepsilon} \nu \omega$ । contradicts it in a contemptuous stressing of Hipp.' unnatural asceticism". 
Em momento posterior do prólogo, diante das estátuas de Ártemis e Afrodite postadas às portas do palácio em Trezena, há um diálogo entre Hipólito e um servo, no qual este adverte seu jovem senhor - que, por ser puro, passa pela Cípria saudando-a de longe

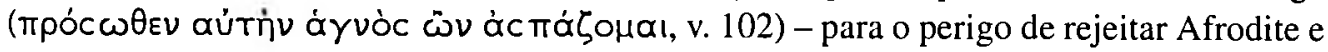
não honrar os deuses. Todavia, Hipólito, um tanto intolerante e arrogante, não lhe dá atenção (vv. 91-113). O servo, preocupado, fala à deusa (Hip. 114-20):

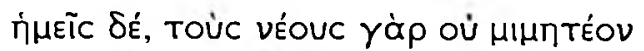

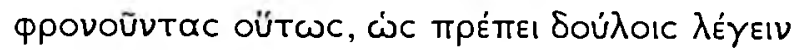

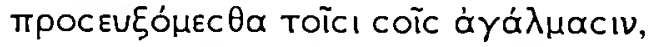

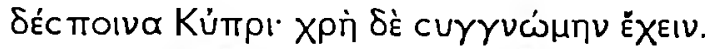

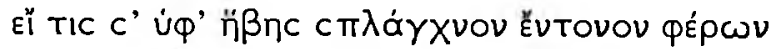

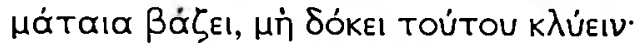

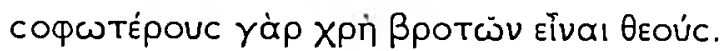

"Nós - pois não devemos imitar os jovens que pensam assim -, como cabe aos escravos falar,

dirigiremos preces às tuas estátuas,

veneranda Cípria: é preciso ser indulgente.

Se o que carrega o coração impetuoso da juventude

diz tolices, faz de conta que isso não ouviste,

pois os deuses devem ser mais sábios que os mortais".

Vã é a advertência do servo a Hipólito; vão é seu pedido a Afrodite, a quem lembra que os deuses, superiores, devem ser mais sábios que os homens. A deusa já selou a fortuna de seu inimigo.

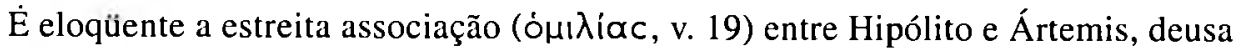
que, tal qual o filho de Teseu, opõe-se à Cípria; o Hino Homérico a Afrodite a inclui entre as três deusas que a rejeitam, dizendo que a Ártemis "das áureas flechas" ( $\chi \rho \cup \sigma \eta \lambda \dot{\alpha} k \alpha$ Tov,

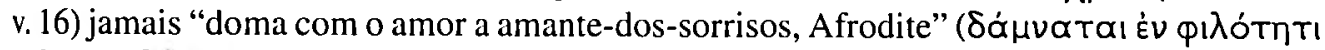

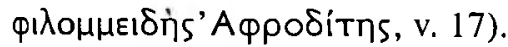

Ressalte-se, na breve passagem do Hino, a conotação erótica do epíteto de Afrodite - que a distingue com perfeição da virgem Ártemis (Boedeker, 1974, p. 24) -, e também

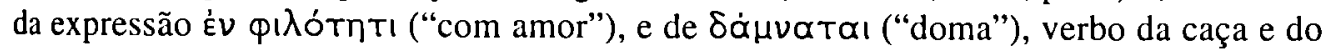
ataque de éros - todos constantes no universo grego do amor erótico.

Tal qual o epíteto, o verbo parece especialmente escolhido, pois tanto na literatura quanto na religião e nos mitos Ártemis, a "caçadora que, triunfante, abate sua presa com arco e flecha" (Burkert, 1998, p. 149), identifica-se com a natureza selvagem. Como a natureza, a deusa é a virgem inviolável; por isso, preside a iniciação das virgens. A virgindade de Ártemis relaciona-se, também, ao antigo ritual da caça, que exigia do caçador pureza e castidade, prerrogativas essenciais para a obtenção de seu favor ${ }^{14}$.

${ }^{14}$ Burkert, 1998, p. 149: "(...) she is also the huntress who triumphantly slays her prey with bow and arrow"; "In the Iliad Artemis is called Mistress of Animals, potnia theron, (...) and this has 
Na tragédia de Eurípides, Hipólito segue essas regras exemplarmente; ele se orgulha de sua pureza e do privilégio que goza junto à virgem caçadora. Bem ilustra isso a cena em que, ao regressar de um "prado virgem" (áknpá Tou/ $\lambda \varepsilon ı \omega \tilde{\nu} \nu 0 c, v v .73-4)$ trazendo flores lá colhidas para Ártemis (vv. 73-78), Hipólito assim lhe fala (Hip. 79-86):

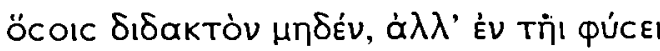
TÒ с 80

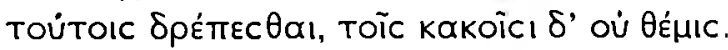

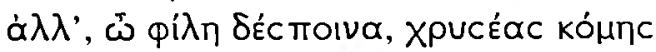

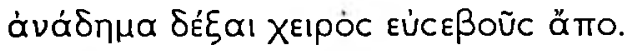

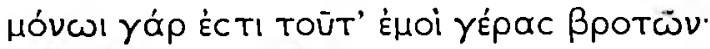

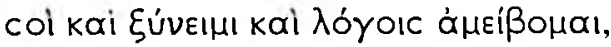

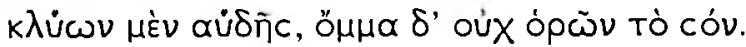

"Os que não foram instruídos, mas em sua natureza

o bom senso herdaram para com tudo sempre esses podem colher-te flores, o que é ilícito aos vis. Mas, ó cara senhora, para os teus áureos cabelos um adorno recebe, de minha mão devota, pois só a mim, dentre os mortais, cabe este privilégio: acompanhar-te e trocar palavras contigo, ouvindo tua voz, sem, no entanto, ver-te".

Não por acaso, Ártemis, no plano divino, e Hipólito, no plano humano, são os inimigos de Afrodite na tragédia. Inexorável, a punição do jovem repercutirá, portanto, em ambos os planos. Nos versos 22-3, Afrodite conta que tudo está planejado há tempos, que alguns passos foram dados, e que pouco resta a fazer. No terceiro bloco do monólogo da peça (vv. 24-40), Afrodite detalha o que já fez. Diz a deusa (vv. 24-33):

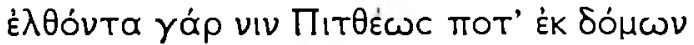

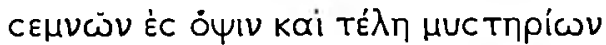

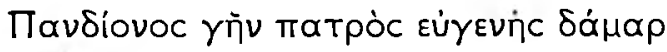

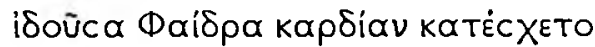

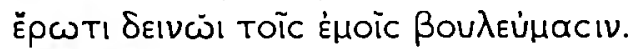

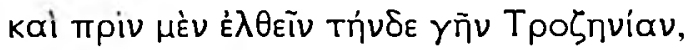 тв́тра

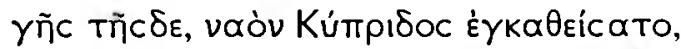

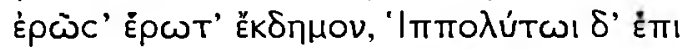

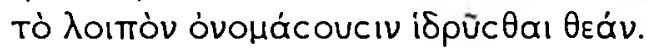

justly been seen as a key to her nature. (...) This Potnia Theron is a Mistress of the whole of wild nature (...) she herself is wild and uncanny (...)"; p. 150-2. Vidal-Naquet, "A Caça e o Sacrifício na Oréstia, de Ésquilo", 1988, p. 139-68. 
"Hipólito, tendo partido da casa de Piteu, certa dia, para ver e contemplar os solenes mistérios

da terra de Pandião - a bem-nascida esposa do pai viu-o, Fedra, e seu coração foi tomado por amor terrível, por meus desígnios.

E antes de vir para esta terra de Trezena, bem ao lado da rocha de Palas, visível desta terra, um templo à Cípria ela construiu, por amor ao amor estrangeiro, e 'sobre o Hipólito' no futuro chamarão o templo erguido para a deusa".

Relevante para o enredo é a paixão de Fedra por Hipólito, mas há que se ressaltar um dado da tradição mítica-religiosa subjacente à peça, qual seja, o templo a Afrodite em Ate-

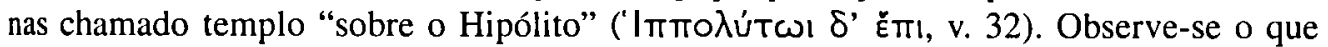
narra Pausânias em seu livro sobre a Ática:

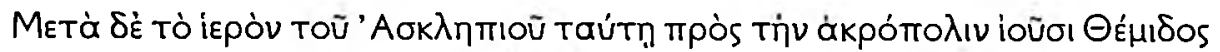

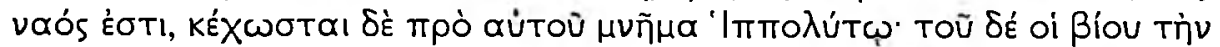

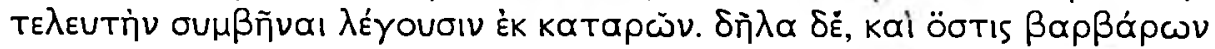

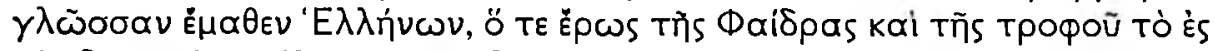

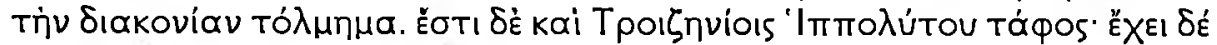

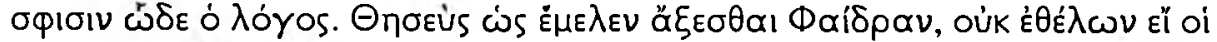

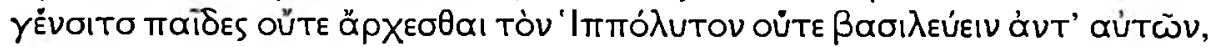

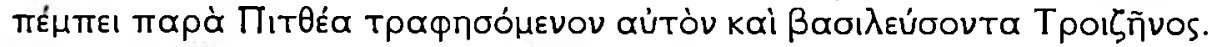

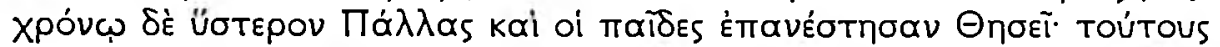

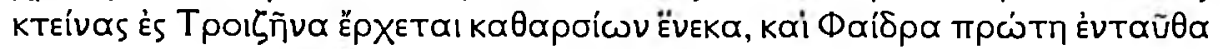

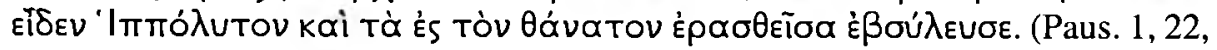
$1-3)$.

"Depois do santuário de Asclépio, indo por esse caminho rumo à acrópole, há um templo a Têmis, e, diante dele, o túmulo de Hipólito. Dizem que sua vida findou por causa de maldições. Estas coisas são evidentes, mesmo para um dos bárbaros que aprendeu a língua dos helenos: o amor de Fedra e o ato ousado da Ama para servir sua senhora. Os trezenos também têm uma tumba de Hipólito, e têm esta estória: quando Teseu estava prestes a desposar Fedra, não desejando que Hipólito fosse governado pelos filhos que viesse a ter com ela e nem que ele os governasse, enviou-o a Piteu para ser por ele criado e para ser o rei de Trezena. Um tempo depois, Palante e seus filhos se rebelaram contra Teseu, que os matou, e, então, partiu para Trezena para se purificar. Lá, Fedra viu pela primeira vez Hipólito e, apaixonada, planejou matá-lo".

Lendo o relato de Pausânias, é possível entender o verso 32 da tragédia de Eurípides, cuja tradução para o nome do templo a Afrodite erguido por Fedra, "sobre o Hipólito"

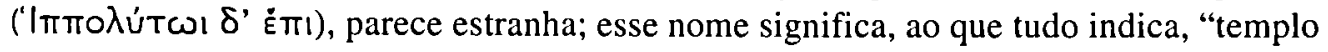
para Afrodite sobre a tumba de Hipólito”. L. R. Farnell frisa, porém, que Pausânias, na passagem acima reproduzida, não menciona o templo referido por Eurípides no Hipólito 
(v. 32), mas somente a tumba do jovem filho de Teseu (Farnell, 1896, p. 658) ${ }^{15}$. Isso gerou polêmicas e indagações, a despeito das quais prevalecem, frente às evidências, opiniões como a de W. S. Barrett, que diz, em Euripides Hippolytos: "Sob a acrópole, em Atenas,

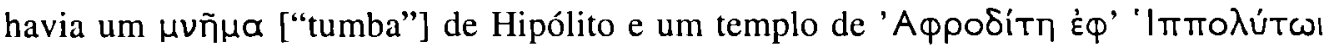
["Afrodite sobre o Hipólito"] (...), e podemos concluir que, quando os atenienses se apossaram da lenda de Hipólito de Trezena, eles falaram desse templo como fundado por Fedra" (Barrett, 1992, p. 37).

Arrolando testemunhos antigos e duas inscrições sobre o templo em questão, $\mathrm{V}$. Pirenne-Delforge arremata, em L'Aphrodite Grecque: "Parece, portanto, segundo essa tradição bastante homogênea, que existia, ao menos a partir de 428 a.C. - data da primeira representação do Hipólito, de Eurípides - um iepóv ["santuário"] ou mesmo um vaós ["templo"] consagrado a Afrodite no flanco da Acrópole que faz face a Trezena, ou seja, no flanco sul" (Pirenne-Delforge, 1994, p. 41).

Barrett afirma, ainda, que o mito ateniense de Hipólito advém do mito de Trezena. Comparando-os, ele observa que, na versão ateniense, Teseu mantém os laços com Trezena, sua terra natal, e, quando adulto, descobre-se filho de Egeu, rei de Atenas, e não de Posídon, rei de Trezena, seu pai na outra versão. Dada a força cultural de Atenas, sua versão prevaleceu na tragédia, em que Teseu figura como seu lendário rei (Barrett, 1992, p. 2).

De volta a Eurípides, nota-se que Afrodite, ao proferir seu monólogo em Trezena espaço da ação - trazendo Atenas à cena como o local onde Fedra se apaixona por Hipólito, aponta para o elo mítico-geográfico entre as duas cidades impresso na tragédia. Quanto a Hipólito, havia um culto antigo a ele em Trezena e outro, menos importante, em Atenas (Barrett, 1992, p. 3; Burkert, 1982, p. 112). Pausânias relata, no livro sobre Corinto:

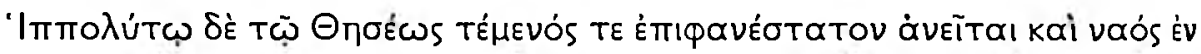

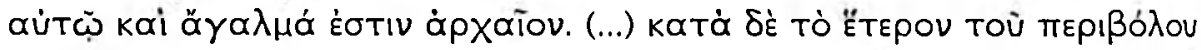

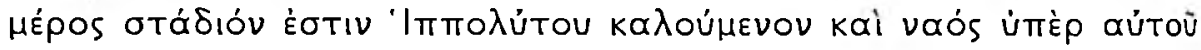

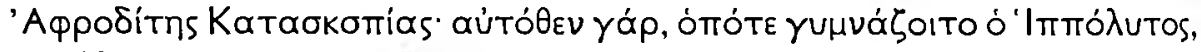

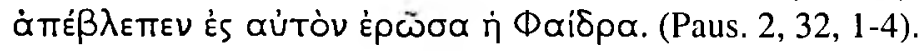

"É dedicado ao filho de Teseu, Hipólito, um precinto sagrado muito famoso e um templo no qual há uma estátua antiga. (...) $\mathrm{Na}$ outra parte da área circundada do recinto, há uma pista de corrida chamada a pista de Hipólito e, acima dela, há um templo de Afrodite, a Observadora, pois longe daqui, quando Hipólito se exercitava, Fedra, apaixonada, lançava seus olhos para ele".

Em Trezena, cidade situada do outro lado do golfo Sarônico, diante de Atenas, Hipólito é um deus, e, perto do seu, há um templo de Afrodite. Essa proximidade se repete em Atenas, onde havia uma tumba ( $\mu \nu \eta \bar{\eta} \mu \alpha)$ de Hipólito perto de um templo de "Afrodite sobre

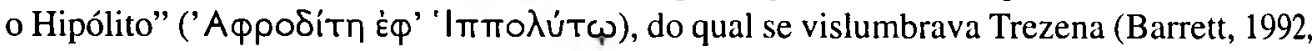

is Cf. Burkert, 1982, p. 112: "We have the word of Pausanias that the Hippolyteion was the major sanctuary of Troezen, with a temple of Aphrodite built within. There was a small sanctuary of Aphrodite 'epi Hippolyto' at Athens, said to be derived from Troezen". 
p. 5). Diz Afrodite no Hipólito que a ela Fedra ergueu, em Atenas, um templo "visível" (káóqiov, 30) de Trezena, de onde a deusa fala e onde havia, atesta Pausânias, um templo a Afrodite "Observadora" (К $\alpha$ т $\alpha \sigma k o \pi i \alpha \varsigma$ ), epíteto que se relacionaria à geografia, de um lado, e, de outro, também ao olhar, sentido que, para os gregos, precedia a paixão (Calame, 1999, p. 21; Goff, 1990, p. 20).

Note-se como age a deusa na tragédia: "viu-o [Hipólito], Fedra, e seu coração foi

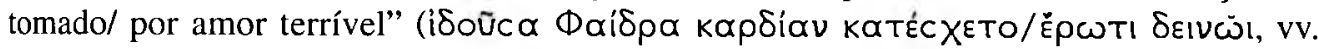
27-8). No Hino Homérico a Afrodite, Zeus age como a deusa ao lançar sobre ela a paixão por Anquises (vv. 56-7). Em ambos, a anterioridade entre "ver" e "amar" é marcada pelo

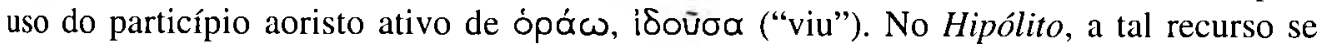

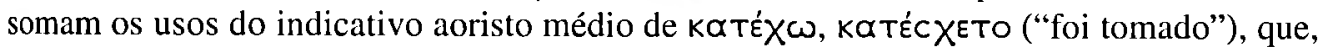

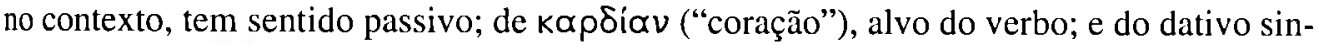
gular ह̌ se modo, um quadro da representação do amor erótico.

Nas descrições de Pausânias sobre Atenas e Trezena, há pontos comuns ao enredo do Hipólito: a paixão de Fedra por Hipólito, fillho bastardo de seu marido; o crime de Teseu em Atenas e sua viagem a Trezena para a purificação; a ação danosa da Ama; a vingança de Fedra contra o jovem; o túmulo de Hipólito e sua morte decorrente de maldições do pai. Um elemento diferente é o local onde Fedra se apaixona por Hipólito, na tragédia: Atenas. Em Trezena, Fedra perece vítima do amor e do silêncio:

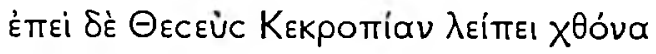

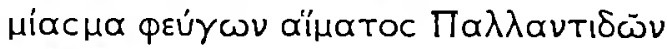

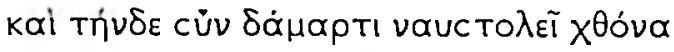

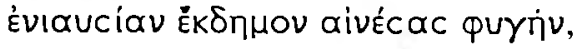

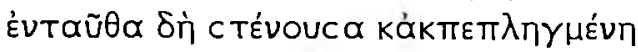

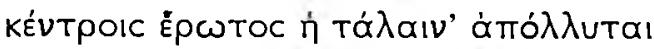

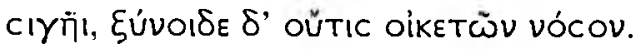

$$
\begin{aligned}
& \text { "Depois que Teseu deixou a terra de Cécrops, } \\
& \text { fugindo da polução do sangue dos filhos de Palante, } \\
& \text { e navegou com sua esposa para esta terra, } \\
& \text { submetendo-se a um ano de exílio no estrangeiro - } \\
& \text { desde então, gemendo e sendo atingida pelos } \\
& \text { aguilhões do amor, a pobre Fedra perece em } \\
& \text { silêncio; nenhuma das servas conhece sua doença. }
\end{aligned}
$$

Em Silence in the Land of Logos, S. Montiglio comenta esses versos: "Afrodite é a primeira a associar morte e silêncio na abertura da peça (...) Afrodite aqui [vv. 39-40] quer dizer que Fedra está morrendo não apenas sem falar, mas também em razão de seu silêncio. De fato, o que mata Fedra é tanto a sua doença quanto a sua resolução de escondê-la. Seu silêncio a mata ao prover-lhe um meio para uma purificação destrutiva" (Montiglio, 2000, p. 234).

A paixão de Fedra é chamada vóøos, "uma doença da mente e do corpo" (Stanford, 1983, p. 36). Segundo os gregos, éros "assalta quem ama de fora e procede a tomar o con- 
trole de seu corpo, sua mente", e representa "uma invasão, uma doença, uma insanidade, um animal selvagem, um desastre natural", cuja ação é "provocar o colapso, consumir, queimar, devorar, exaurir, entontecer, picar, aguilhoar, (...)" (Carson, 1986, p. 148). Esse éros permeia o discurso de Afrodite e se revela na definição da Ama, dita a Fedra, do que é

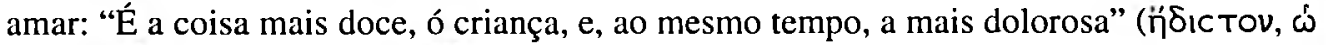

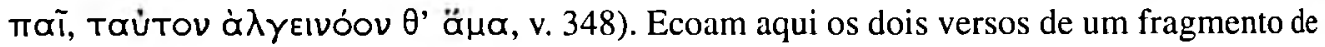
Safo (Fr. 130 V, edição Voigt, 1971):

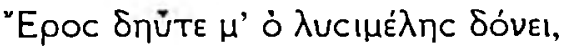

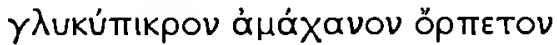
... Éros de novo - o quebra-membros - me agita, doce-amarga inelutável criatura ...

Veja-se, ainda, o retrato de Éros no hino a ele entoado pelo coro de mulheres trezenas no primeiro estásimo da tragédia de Eurípides (Hip. 525-542):

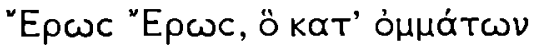

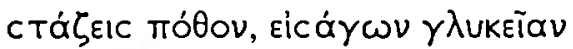

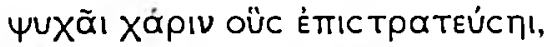

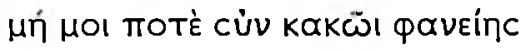

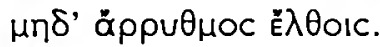

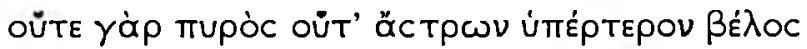

ốov tó Tãc 'A

"Epwc ò $\Delta$ iòc maíc.

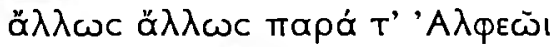

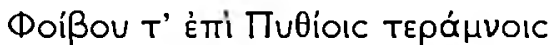

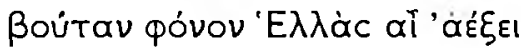

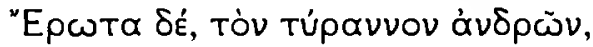

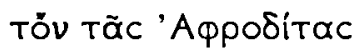

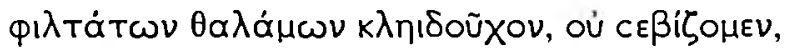

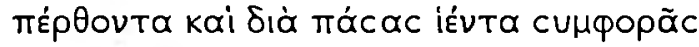

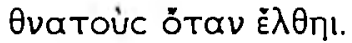

“Ó Éros, Éros, que nos olhos

destilas o desejo, levando o doce

encanto à alma dos que atacas,

jamais com males te reveles a mim,

nem me venhas sem medida.

Pois nem os dardos do fogo e nem os dos astros

são mais poderosos que os de Afrodite, que lança das mãos Éros, o filho de Zeus. 
Em vão, em vão, junto às margens do Alfeu

e sob o templo de Febo, em Delfos,

a Hélade acumula sacrifícios de gado, se Éros - o tirano dos homens,

dos aposentos adorados de

Afrodite o guardião das chaves - não cultuamos;

540 .

ele que marcha devastando tudo, infortúnios trazendo aos mortais quando vem".

Doce a princípio, amargo depois: éros é uma experiência de prazer e de sofrimento este o seu aspecto mais marcado na Grécia antiga. A ordem dos termos não parece gratuita em Safo, nem tampouco na fala da Ama. Para Fedra, a paixão-doença causará dor e será fatal, mas isso não saciará a ira de Afrodite, que diz, encerrando o monólogo inicial da tragédia (Hip. 41-57):

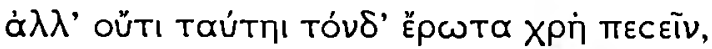

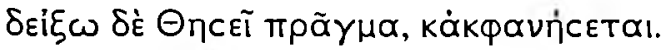

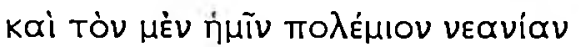

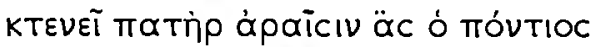

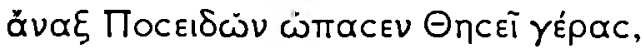

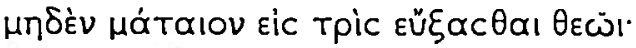

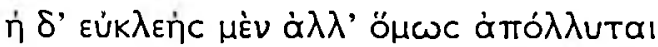

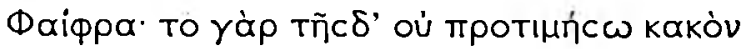

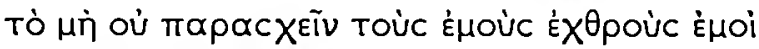

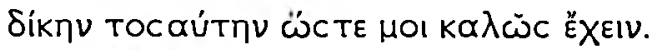

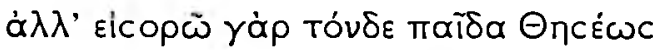

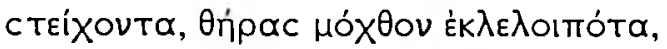

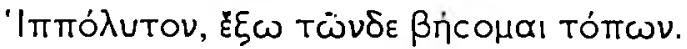

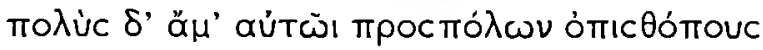

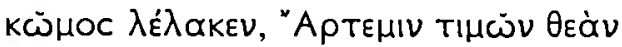

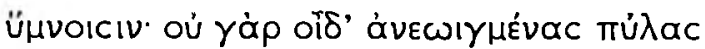

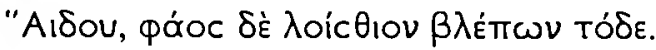

"Porém, não deve essa paixão acabar assim.

Eu mostrarei o feito a Teseu e ele será revelado.

O pai matará meu jovem inimigo com

maldições que o senhor marinho,

Posídon, concedeu a Teseu como privilégio:

que em vão não seja sua tripla prece ao deus.

Fedra, embora bem reputada, morrerá,

pois eu não estimarei seu mal

a ponto de poupar meus inimigos

da punição tal que me seja a melhor. 
Mas eu irei embora deste lugar, pois

vejo que este filho de Teseu, Hipólito, aproxima-se,

tendo deixado o trabalho da caça.

Muitos servos vêm com ele, seguindo-o, e o

grupo grita e canta hinos honrando a deusa

Ártemis. Hipólito não sabe que estão abertas para ele

as portas do Hades e que ele vê, pela última vez, esta luz".

Se antes Afrodite contou o que já realizara para concretizar sua vingança (vv. 22-40), ela agora nos diz qual a etapa final: contar a Teseu sobre a paixão de Fedra por Hipólito. Assim, a deusa esmagará suas vítimas: Hipólito será morto pelas três maldições sobre ele lançadas por Teseu, seu pai, e Fedra, embora renomada, será morta. Esta última revelação surpreende, porque Afrodite declarou honrar os que a reverenciam (vv. 5-8). Fedra a honrou, erguendo-lhe, em Atenas, um templo (vv. 27-40); portanto, mereceria benevolência, não custasse isso a vingança da deusa - um preço alto demais (vv. 48-50) ${ }^{16}$.

Conclui-se que Fedra é instrumento e vítima de Afrodite, cuja cólera recai sobre ela e sobre Hipólito, abatendo-os impiedosamente. Afirma V. Pirenne-Delforge, em L'Aphrodite Grecque: "As cóleras da deusa concernem sistematicamente atitudes de desvio referentes a práticas sexuais que qualificaríamos de 'normais'. Quer seja de abstinência ou de excesso, a hybris sexual dos heróis míticos é violentamente sancionada pela deusa, isso quando tais desvios não são já a punição enviada por ela (...). A origem mais freqüente dessa punição se caracteriza por uma recusa da submissão aos poderes divinos concretamente traduzida, no plano ritual, pela ausência de homenagens rendidas à deusa (...)" (Pirenne-Delforge, 1994, p. 460). Os erros de Hipólito consistem em abstinência e não reverência a Afrodite (vv. 1322): tais erros, frutos da imprudência, da arrogância e da intolerância evidenciadas na tragédia (vv. 91-120), custarão ao jovem sua própria vida.

No politeísmo, "muitos deuses são adorados não apenas no mesmo lugar e ao mesmo tempo, mas pela mesma comunidade e pelo mesmo indivíduo"; ignorar um dos deuses pode ser fatal (Burkert, 1998, p. 216). Puro, casto e fiel a Ártemis, Hipólito rejeita e difama Afrodite, uma atitude que não ficará impune, conta a deusa ao ver chegar da caça o alegre jovem queignora viver seu último dia (vv. 51-7). A deusa deixa o palco ao qual não voltará, mas suas palavras pesarão sobre a tragédia como o prenúncio da desgraça e da morte por sua cólera engendradas.

16 Cf. Saïd, 1978, p. 229-30: “(...) si Aphrodite perd, avec le héros, Phèdre, Thésée et toute la maison, ce n'est pas qu'elle veuille faire payer à une famille entière la faute commise par l'un de ses membres, c'est uniquement parce que la mort de Phèdre est la condition nécessaire du châtiment d'Hippolyte et que la ruine de Thésée est la conséquence inévitable du suicide de sa femme et de la mort d'un fils qu'il a provoquée lui-même par ses malédictions. C'est donc un peu par hasard que le malheur s'abat sur Phèdre et sur Thésée. C'est en tout cas fort injustement, comme le souligne Euripide. Car les dieux eux-mêmes, que ce soit Aphrodite dans le prologue ou Artémis dans l'épilogue, reconaissent la glorieuse résistence de Phèdre et sa noblesse, et l'absolution de Thésée par Hippolyte contribue à mettre en relief le caractère immérité du malheur qui le frappe". 


\section{Considerações finais}

Muito se questionou a importância desse monólogo, uma vez que Afrodite conta o que se vai passar no Hipólito. Porém, é preciso atentar para um fato essencial: a deusa não diz com precisão como o amor de Fedra por Hipólito será a ruína de ambos, nem diz o que será de Teseu e como ele tomará ciência de tudo, e tampouco menciona a Ama, o ponto de ligação dos acontecimentos. Ao omitir tais informações, o monólogo, ao contrário do que possa parecer, intensifica o suspense, o mistério, servindo, pois, para aumentar a tensão da platéia e do leitor.

Em sua tragédia, valeu-se Eurípides de um mito trezeno-ateniense decerto familiar aos seus espectadores; Pausânias diz que o mito era bastante conhecido: $\delta \tilde{n} \lambda \alpha \delta \varepsilon$, kai

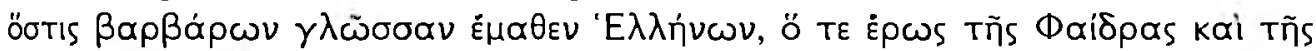

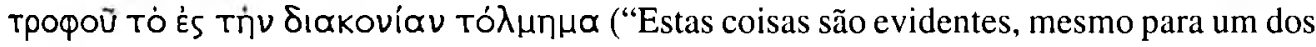
bárbaros que aprendeu a língua dos helenos: o amor de Fedra e o ato ousado da Ama para servir sua senhora") (Paus. 1, 22, 1). Todavia, o poeta apropria-se do mito trezeno, fazendo dele uma leitura específica. Os destinos de Fedra e Hipólito nos mitos não eram ignorados, mas como a tragédia os resolverá nem mesmo Afrodite revela. Por isso, o público, provavelmente, não se ia antes do fim da encenação; por isso, nós, leitores, não fechamos o Hipólito até a linha final.

Sabe-se que Eurípides é autor de duas peças chamadas Hipólito. Na primeira, cuja data é desconhecida, "adotou a lenda tradicional sem modificação: Fedra era a desavergonhada mulher sem princípios que, quando se apaixonou por Hipólito, fez uma tentativa deliberada de seduzi-lo; ele a repeliu e ela, com raiva e em defesa própria (caso ele a acusasse a Teseu), acusou-o de estupro ou tentativa de estupro a Teseu. Este amaldiçoou o filho, Posídon enviou o touro e Hipólito foi morto. Então, aparentemente, a traição de Fedra foi exposta; por isso, ela se matou" (Barrett, 1992, p. 11).

Assim concebido, o primeiro Hipólito fracassou, pois o amor ilícito de Fedra e seu comportamento desagradaram os atenienses (Barrett, 1992, p. 12). Já em 428 a.C., com a segunda tragédia - a que sobreviveu -, Eurípides foi premiado, porque mudou o perfil de Fedra, tornando-a virtuosa e envergonhada do sentimento que cala, determinada antes a morrer do que revelar sua paixão por Hipólito, como diz Afrodite no monólogo (vv. 38-40) (Barrett, 1992, p. 13-5).

Se Fedra, vítima e instrumento da Cípria (Méridier, 1911, p. 75), leva Hipólito à morte ao acusá-lo de estupro, injustamente, em carta a Teseu (vv. 856-890), ela o faz para salvar sua honra porque, ao saber de tudo pela Ama, o jovem ameaçou denunciá-la ao pai. Depois, atendendo aos apelos da Ama, concordou em silenciar os fatos, mas Fedra disso não soube (vv. 601-668). Hipólito jurou nada dizer a Teseu e, às custas de sua vida, será fiel a sua palavra em confronto com o pai. Teseu, diante do corpo de Fedra, da terrível acusação que a sua carta grita (v. 877), e do silêncio do filho, condena-o ao exílio (vv. 902-1101) amaldiçoando-o. Todavia, quando o Mensageiro relata a ele o encontro mortal entre Hipólito - que partia de Trezena desesperado a dirigir sua carruagem - e um touro saído do mar o presente de Posídon em resposta às maldições de Teseu -, Ártemis entra em cena para 
esclarecer os fatos, mostrando a Teseu que ele errou ao condenar Hipólito, um inocente, pois todo o ocorrido foi planejado e executado por Afrodite (vv. 1283-1312). Então, com a permissão do pai, Hipólito, moribundo, é trazido ao palco. Pai, filho e a virgem Ártemis conversam; Hipólito, a quem a deusa esclarece que tudo foi obra da Cípria, perdoa o pai que sumariamente o julgou e puniu, sem levar em conta seu caráter e seu bom comportamento (vv. 1348-1451). Diz Ártemis:

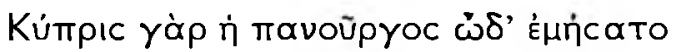

"Pois a Cípria, a velhaca, assim planejou".

A deusa reitera a Hipólito os motivos de Afrodite que esta explicitou no início da tragédia (vv. 12-16) (v. 1402):

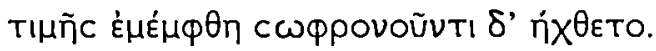

"Censurava a falta de honras e odiou-te por seres casto".

Estarrecido, Hipólito percebe que ele, seu pai e Fedra são as vítimas da Cípria (v. 1403):

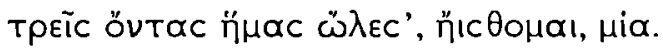

"A nós, sendo três, ela - compreendo - destruiu, sendo uma".

Esse encerramento joga sobre Afrodite grande responsabilidade pela desgraça das personagens. Bem antes, na abertura da tragédia, a terrível deusa já se assumia mentora do plano de vingança contra Hipólito. Contudo, Afrodite omitiu que o jovem morreria devido à falsa acusação da carta de uma morta, Fedra, que queria resguardar sua reputação. Se ele não é inocente por ter, orgulhoso, rejeitado a Cípria e deixado de honrá-la, como ela alega, diga-se também que ele nunca tentou estuprar Fedra (Knox, 1986, p. 223).

Pode-se concluir, portanto, que o monólogo é um recurso concebido propositadamente, pois ao atribuir à deusa a responsabilidade pelos erros humanos, inocenta Fedra, Teseu e até Hipólito, todos vítimas dignas de simpatia e piedade (Knox, 1986, p. 226-7). Além disso, o discurso de Afrodite - colérica, poderosa e violenta - suscita no espectador sentimentos fortes e, na medida em que revela e esconde o que se vai passar, instaura uma atmosfera de apreensão e suspense que contribui para que a tragédia atinja em cheio sua platéia - e seu leitor -, deixando-a sem fôlego, exaurida e comovida pelo sofrimento das personagens.

\section{Referências Bibliográficas}

ALLEN, T. W.; HALLIDAY, W. R.; SIKES, E. E. (Eds.). The Homeric Hymns. Amsterdam: Adolf M. Hakkert, 1980. 
BARRETT, W. S. Euripides Hippolytos. Oxford: Clarendon Press, 1992.

BOEDEKER, D. D. Aphrodite's Entry into Greek Epic. Lugduni Batavorum: Brill, 1974. (Mnemosyne, Supplementum 32).

BRUNA, J. Teatro Grego. 2. ed. São Paulo: Cultrix, 1968.

BURKERT, W. Greek Religion. Translation by John Raffan. Cambridge: Harvard University Press, 1998.

. Structure and History in Greek Mythology and Ritual. Berkeley: University of California Press, 1982.

CALAME, C. The Poetics of Eros in Ancient Greece. Translation by Janet Lloyd. Princeton: Princeton University Press, 1999.

CAMPOS, H. de. (Trad.). llíada de Homero: volume I. São Paulo: Mandarim, 2001.

CARSON, A. Eros, the Bittersweet: an essay. New Jersey: Princeton, 1986.

DETIENNE, M., SISSA, G. Os Deuses da Grécia. Tradução de Manuela Madureira. Lisboa: Editorial Presença, 1991.

DODDS, E. R. The AI $\triangle \Omega \Sigma$ of Phaedra and the Meaning of the Hippolytus. CR, v. 39, p. 102-4, 1925.

. The Greeks and the Irrational. Berkeley: University of California Press, 1953.

EVELYN-WHITE, H. G. Hesiod, Homeric Hymns, Epic Cycle, Homerica. Cambridge: Harvard University Press, 1998. (The Loeb Classical Library).

FARNELL, L. R. The Cults of the Greek States-II. Oxford: Clarendon Press, 1896.

FERGUSON, J. Euripides Hippolytus. Bristol: Bristol Classical Press, 1994.

FOLEY, H. (Ed.). Reflections of Women in Antiquity. Philadelphia: Gordon and Breach, 1992.

FRIEDRICH, P. The Meaning of Aphrodite. Chicago: The University of Chicago Press, 1978.

GARRISON, E. P. Attitudes Toward Suicide in Ancient Greece. TAPA, v. 121, p. 1-34, 1991.

GERNET, L.; BOULANGER, A. Le Génie Grec dans la Religion. Paris: Albin Michel, 1970.

GOFF, B. E. The Noose of Words. Readings of desire, violence and language in Euripides' Hippolytus. Cambridge: Cambridge University Press, 1990.

GOLDHILL, S. Reading Greek Tragedy. Cambrige: Cambridge University Press, 1992.

GRUBE, G. M. A. The Drama of Euripides. London: Methuen \& Co. Ltd., 1941.

HALLERAN, M. R. Gamos and Destruction in Euripides' Hippolytus. TAPA, v. 121, 1991, p. 109-21.

HERODOTUS. The Persian Wars. Books I-II. Translation by A. D. Godley. Cambridge: Harvard University Press, 1999. (The Loeb Classical Library). 
HESÍODO. Teogonia: a Origem dos Deuses. Tradução de Jaa Torrano. 3. ed. São Paulo: Iluminuras, 1995.

HEUBECK, A. et alii. A Commentary on Homer's Odyssey. Volume I: introduction and Books I - VIII. Oxford: Clarendon Press, 1991.

HOMÈRE. Iliade. Tome I (Chants $I-V I$ ). Traduit par Paul Mazon. $8^{\mathrm{c}}$ éd. Paris: Les Belles Lettres, 1987.

HOMER. The Odyssey $-I$. Translation by A. T. Murray. Cambridge: Harvard University Press, 1976. (The Loeb Classical Library).

HOOKER, J. T. Homer. Iliad III. Bristol: Bristol Classical Press, 1979.

HOUAISS, A. et alii. Dicionário Houaiss da Língua Portuguesa. Rio de Janeiro: Objetiva, 2001.

JOUAN, F. Euripide et les Légendes des Chants Cypriens. Des origines de la guerre de Troie à l'lliade. Paris: Belles Lettres, 1966.

KIRK, G. S. The Iliad: a commentary - I: books 1-4. Cambridge: Cambridge University Press, 1995.

. The Iliad: a commentary - Il: books 5-8. Cambridge: Cambridge University Press, 1995.

KITTO, H. D. F. A Tragédia Grega. Tradução de José Manuel C. e Castro. Coimbra: Arménio Amado, 1990. 2 vols.

KNOX, B. The Hippolytus of Euripides. In: Word and Action. Essays on the Ancient

Theater. Baltimore: The Johns Hopkins University Press, 1986, p. 205-30.

KOVACS, D. The Heroic Muse. Studies in the Hippolytus and Hecuba of Euripides.

Baltimore: The Johns Hopkins University Press, 1987, p. 22-77.

LAWALL, G. \& S. Euripides Hippolytus. Bristol: Bristol Classical Press, 1986.

LESKY, A. A Tragédia Grega. São Paulo: Perspectiva, 1971.

LIDELL, SCOTT \& JONES. Greek-English Lexicon with a Revised Supplement. $9^{\text {th }}$ ed Oxford: Clarendon Press, 1996.

LLOYD-JONES, H. The Justice of Zeus. Berkeley: University of California Press, 1971. MÉRIDIER, L. Euripide - Tome II - Hippolyte, Andromaque, Hécube. Paris: Belles Lettres, 1965.

. Hippolyte d'Euripide. Paris: Librairie Mellotteé, [1930].

. Le Prologue dans la Tragédie d'Euripide. Bordeaux: Feret \& Fils, 1911.

MONTIGLIO, S. Silence in the Land of Logos. Princeton: Princeton University Press, 2000. MORGAN, G. Aphrodite Cytherea. TAPA, v. 108, p. 115-20, 1978.

PAUSANIAS. Description of Greece - I. Books $I-I I$. Translation by W. H. S. Jones. Cambridge: Harvard University Press, 1959. (The Loeb Classical Library).

. Description of Greece - II. Books III-V. Translation by W. H. S. Jones. Cambridge: Harvard University Press, 1955. (The Loeb Classical Library). 
. Description of Greece - III. Books VI - VIII. Translation by W. H. S. Jones. Cambridge: Harvard University Press, 1954. (The Loeb Classical Library).

. Description of Greece - IV. Books VIII-X. Translation by W. H. S. Jones. Cambridge: Harvard University Press, 1955. (The Loeb Classical Library).

PIRENNE-DELFORGE, V. L'Aphrodite Grecque. Contribution à l'étude de ses cultes et de sa personnalité dans le panthéon archaïque et classique. Athènes - Liège: Centre International d'Étude de la Religion Grecque Antique, 1994.

POWELL, A. (Ed.). Euripides, Women, and Sexuality. London: Routledge, 1990.

ROMILLY, J. De. A Tragédia Grega. Tradução de Ivo Martinazzo. Brasília: Ed. UnB, 1998. SAÏD, S. La Faute Tragique. Paris: François Maspero, 1978.

SALE, W. Aphrodite in the Theogony. TAPA, v. 92, 1961, p. 508-21.

SEGAL, C. Euripides and the Poetics of Sorrow. Art, Gender, and Commemoration in Alcestis, Hippolytus and Hecuba. London: Duke University Press, 1993.

SEGAL, E. (Ed.). Oxford Readings in Greek Tragedy. Oxford: Oxford University Press, 1983. STANFORD, W. B. Greek Tragedy and the Emotions. An introductory study. London: Routledge \& Kegan Paul, 1983.

VIDAL-NAQUET, P. “A Caça e o Sacrifício na Oréstia, de Ésquilo”. In: , VERNANT, Jean-Pierre. Mito e Tragédia na Grécia Antiga. São Paulo: Brasiliense, 1988, p. 139-68, vol. I.

VOIGT, E.-M. Sappho et Alcaeus: fragmenta. Amsterdam: Athenaeu - Polak \& Van Gennep, 1971.

WALKER, H. J. The Early Developments of the Theseus Myth. RMPh, v. 138, p. 1-33, 1995. WAY, A. S. Euripides - IV. Ion, Hippolytus, Medea, Alcestis. Cambridge: Harvard University Press, 1958. (The Loeb Classical Library).

WEST, M. L. (Ed.). Hesiod. Theogony. Oxford: Clarendon Press, 1988.

* Este artigo, com alterações, consiste no trabalho de aproveitamento de curso de pós-graduação, que fiz em 2001, para a Profa. Dra. Filomena Hirata, a quem agradeço a disponibilidade e a leitura atenta do texto.

RAGUSA, Giuliana."Wrath, passion and death: the representation of Aphrodite in Euripides" Hippolytus". Classica, São Paulo, 15/16, p. 79-98, 2002/2003.

ABSTRACT: This article is a study on Aphrodite's character in the Hippolytus of Euripides, where she is represented under the signs of wrath, of passion and of death. Its focus of analysis is the monologue of the goddess with which she opens the tragedy and after which she leaves the stage never to return. Besides the monologue, other few references to the goddess in the tragedy will be taken under consideration, as well as reports of ancient sources, passages of epic poems 
and studies on Greek cult and religion. By doing so, I expect to emphasize the singularity of Aphrodite's character in the Hippolytus as it was conceived by Euripides, and also to identify echos of the many literary and cultic Greek "Aphrodites".

KEYWORDS: Aphrodite; Hippolytus; Euripides; wrath; passion and death. 